\title{
Editorials
}

\section{The microbiome:}

what it means for medicine

It is impossible not to notice the enormous surge in human microbiome research the past decade, new molecular methods have started to unlock the secrets of this unseen universe, and suddenly is towning on us that human individuals are not the dominant life-form in the symbiosis of our existence. It is often quoted that humans are $10 \%$ human and $90 \%$ microbial when a comparamive count of cell numbers is astonishingly, it is now clear that our human microbiome the collection of genes encoded by our microbial passengers, is at least one hundred-fold greater than our own genome. The diversity of the human 'microbiota' is enormous, with approximately 500-1000 species existing in our gastrointestinal tracts alone. We are the vessels for his community yeasts) living on us and in us, and as we start to unravel the multitude of roles that this microbiota fulfils, it is becoming clear that our microbes play a far more relevant and important role in the maintenance of our health than we have ever stopped to reason that we are at ar, $h$ stands to our attitude towards microbes in point in context.

\section{ADJUSTING OUR PERCEPTION OF}

'GERMS'

From an early age most of us are taught that germs are bad and that we need to avoid them wherever possible. For clinicians, there is further reinforcement of small but significant number of microbes that are pathogenic to us. Infectious disease continues to be a major threat to health despite the medical advances we have made in the past few decades. The success of antibiotic therapy heralded a new era in our collective consciousness that, in the words in 1967, boldly suggested that it was the in ' The medical over-confidence that followed saw the use of antibiotics spread from the treatment of life-threatening infections to the treatment of less serious disease, from mild otitis media to acne. Now in 2014 we have realised the error of our ways, as we witness the widespread and increasing emergence rightly, this is forcing a re-examination of the in both medical as well as administration practices ffor example, farming, where the Food and Drug Administration estimated the annual amount of non-therapeutic antibiotics administered to animals in the US in 2011 alone as 24.6 million lbs lalmost 13500 tonnes), and encourage restriction on the use of these drugs wherever possible. Howner, the conlining study of the tar more ominous side effect of antibiotic use: the concomitant loss of our residen microbiota. Our resident microbes are engaged in a complex partnership- with our human selves that has co-evolved with us over milennia. These microbes have recently been revealed to have functions beyond heir clcar role as niche dwellers that These

sites and between residen across body. The microbiota is known to 'educate' the mmune system, steering it away from needless attacks on commensal microbes such that its efforts can be concentrated on real threats. The gut microbiota also plays role in breakdown of complex dietary compounds, provision of key molecules and as B vitamins), and even makes (such poorly understood) contributions to mood behaviour and sleep patterns.

CONSEQUENCES OF COLLATERAL

DAMAGE IN ANTIMICROBIAL THERAPY Antimicrobials, and in particular those th are broad-spectrum in nature, are never simply targeted towards pathogens; in the heawy collateral damage on the indigenous microbiota. Fortunately, the microecology of the healthy human microbiota is highly diverse and carries 'functional redundancy.

the capacity for multiple microbes within he same ecosystem to carry out the same ability to withstand antibiotic-inflicted stress and to recover from it. However, because we all have a microbiota that is uniquely shaped by our environment and by other factors that are less well understood, this exclusivity means that it is not yet possible to predict individual responses to antimicrobial exposure. Furthermore, microbial ecosystems at critical points development lin particular, early childhood. may result in long-lasting damage that is not easily reversible and may lead to later susceptibility to chronic diseases such as inflammatory bowel disease, asthma, atopy, diabetes, obesity, and even autism. We understand me extent to which microbiota damage on human health we can look to a clear example where microbiota collapse is the underlying cause of disease: Clostridium difficile infection (CDII). The circumstances that give rise to $\mathrm{CD}$ usually reflect collateral damage on the gut microbiota brought about by incidental antibiotic use, which allows $C$. difficile to proliferate and thrive withour a healhy microbicta to regulate its is further antimicrobial therapy with either oral vancomycin or metronidazole, it is not surprising that the infection can recur, and a vicious cycle of pathogen expansion followed by antimicrobial suppression (but not clearancel can ensue." The ability of faecal microbial therapy (FMT, or 'stool transplant') to rapidy and effectively clear infection and is a clear indication of the power of the microbiome in the restoration of health. We and others have made steps to refine this somewhat primitive procedure through
It is time to shift emphasis from the common perception that "the only good germ is a dead germ".

the selection of particular health-associated gut microbes for the development Ecosystem Therapeutics,' (MET) thereby improving safety, controllability, and overal acceptability. alongside nutritional counselling to advise management and maintenance of their beneficial colonic microbes.

microbiome to treat disease and maintain health is thus the next step in the journey into a new era of medicine. While physicians have already begun . of microbes as potentially life saving then is still much work to be done to educate the general public in this respect. It is time to shift emphasis from the common perception that 'the only good germ is a dead germ, and to instead focus on elucidating the beneficial effects that can be reaped from wise management of our microbiome. Reduced patient insistence on unnecessary antibiotic new understanding.

\section{CONCLUSION}

ways have an important place in medicine, but their use may need to become more limited and defined. With more attention focused on targeted approaches to pathogen removal, we can in terms of reducing antibiotic resistance and in reducing collateral damage inflicte on our microbiome. In the future, rather problem by implementing instruments scalating host-versus-microbe warfare such as antibiotics, physicians may instead be required to be the brokers of peace agreements within the bodies of their patients, through new strategies involving manipulation and fine tuning of th

\section{Emma Allen-Vercoe,} Associate Professor, Department of Molecular
and Cellular Biology, University of Guelph, Guelph,
Ontario, Canada.

\section{Elaine 0 Petrof,}

Associate Professor, Department of Medicine,
Kingston General Hospital, Queen's University,

Provenance
Antimicrobials, and in particular those that are broadspectrum in nature, are never simply targeted towards pathogens; in the battlefield of infection these drugs inflict heavy collateral damage on the indigenous microbiota.
ADDPESS FOR CORPESPONDENCE

Tmmallen-Vercoe

Department of Molecular and Cellular Biology,
University of Guelph, 50 Stone Road East, Guelph, E-mail: eavauoguelph.ca

REFERENCES

Ley RE, Peterson DA, Gordon Jl. Ecological diversity in then humanan intestine. Cell 2006:

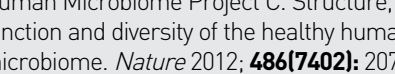

Upshur R. Ethics and infectious alsease

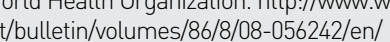

of Heatth and Human Services. Summary
of

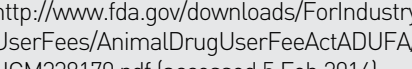

Rjilic-Stojanovic M. Function of the
icrobiota. Best Pract Res Clin Gastroenterol

2013; 27(1): $5-16$

microbiotat to humanarnere F. Linking the gur

(. Use S, Sogin ML, Relman DAA un e280.

Haahtela T, Holgate S, Pawankar R, et al. The world allergy organization position statement World Allergy Organa J 2013; 611 : 1 : 3 .

Petrof EO, Claud EC, Gloor GB, Allen-Vercoe
E. Microbial ecosystems therapeutics: a new paradigm 41 : $53-65$

Shaw SY, Blanchard JF, Bernstein CN.

Association between early childhood otitis

disease: an exploratory population-based
analysis. J Pediatr 2013; 16233: $510-514$.

Knight CL, Surawicz CM. Clostridium difficile
infection. Med Clin North Am 2013; 97144:

23-536,

Smits LP, Bouter KE, de Vos WM, et al.
Therapeutic potential of fecal micrat.

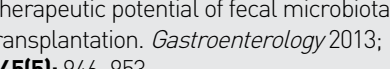

Allen-Vercoe E, etal. A Canadian Working Group Report on fecal microbial therapy:
microbial ecosystems therapeutics. Can Gastroenterol 2012; 2617):457-462

Etrof EO, et al. Stool substitute transplant

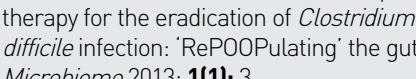

